\title{
REAL-LIFE LEARNING IN HIGHER EDUCATION
}

\author{
Embedding and modelling the effective use of ICT
}

\author{
Paul Nicholson and Geoff White \\ Faculty of Education, Deakin University, Australia \\ pauln@deakin.edu.au and geoffw@deakin.edu.au
}

\begin{abstract}
While real-life learning is commonly identified with workplace or lifelong learning outside of an individual's initial pre-workforce education, this does not preclude real-life learning experiences occurring within Higher Education programs. This paper describes a program that aims to integrate real-life learning experiences into a pre-service teacher education program in a way that provides rich, contextualised learning experiences, provides a basis for meeting the requirements of external certification criteria that focus on evidence-based performance rather than on academic competencies, and provides students with authentic learning experiences in the effective use of ICT in their professional roles and classroom-based work.
\end{abstract}

Key words: Teacher education, higher education, practicum, problem-based learning.

\section{INTRODUCTION}

While 'real-life' learning is commonly identified with workplace or lifelong learning outside of an individual's initial pre-workforce education in the school and Higher Education sectors, this does not preclude real-life learning experiences occurring within Higher Education programs. In particular, in those programs that focus on the development of performancebased expertise in professional practice - such as in teaching, the Arts, and in medicine - the use of real-life workplace-based learning experiences has the potential to greatly enrich and enhance learners understandings and skill development. Putnam \& Borko (2000) argue that such contextualised 
experiences are critical for the effective development of teachers' thinking. These may also form the basis of reflective praxis (Kane, 1999) and life-long learning around pedagogy and educational practices (Levin, 2003). The common lack of connection between school and post-school learning (Fig, 1) often means that learning in schools is seen as an end in itself, with little relevance to subsequent life. However, Walsh \& Cripps Clarke (elsewhere in this volume) have shown that connections between work contexts and formal education are important in the development of expert teachers.

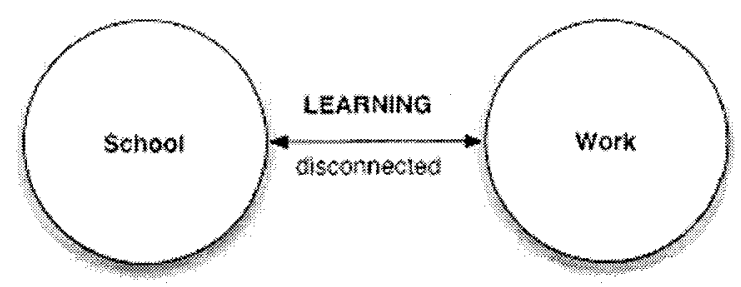

Figure 1. Traditional school to work learning development

The use of workplace contexts and real-life learning helps to ensure that such programs accommodate learners' concerns and contemporary developments, and that they meet learners' expectations of acquiring practical and up-to-date knowledge that is applicable in their workplace something very important to learners involved in ongoing practicum programs. Countering this possible advantage is the need to ensure that such programs also provide learners with a wide range of professional and academic knowledge about conceptual, practical and policy issues that can be applied to a wide range contexts - and not just those developed in or around one particular context or practicum experience. It is therefore necessary to ensure that such programs are designed around a blended learning model that provides learners with workplace, professional, and academic perspectives.

By providing overlap between school-based and real-life learning, learners have the opportunity to reflect on the relationships between them and to develop rich understandings of the reciprocal relevance and application of their school-based learning to the workplace. Such contextualised self-reflective processes are a central element of lifelong learning and foundational to the development of effective teaching (e.g., Berliner, 1991) and the development of praxis at an early career stage. It is hoped that this will be a useful foundation for the learners' lifelong professional learning (both formal and 'real-life'). Curiously, the PBL is not widely used in teacher education programmes, where didactic approaches 
and traditional curricula seem to be resilient to change (cf. Nicholson, 1995, 2004; Nicholson \& deWacht, 2002).

\section{THE CONTEXT}

The context of this paper is the semester-long unit 'Creating Effective Learning Environments' (CELE) - one of six units of the 'Education Studies Major' (ESM) program in the Faculty of Education at Deakin University. The ESM aims to provide students with a broad range of academic and professional knowledge and skills that meet the diverse needs of graduate teachers. Other units in the ESM cover developmental and learning issues, curriculum models and influences and the development of particular curricula. Methodological issues in particular content areas are addressed in a separate series of 'methods' units. Students also undertake an extensive practicum program over the duration of their degree. Students in the ESM include recent school graduates, mature age learners making a career change to teaching, and international students. The ESM program is delivered face-to-face on three campuses at Burwood, Geelong Warrnambool. It is also offered in off-campus mode.

The focus of CELE is on educational policy, classroom management and planning, and to develop the students' ICT skills and their awareness of its educational potential for supporting engaging and inclusive learning environments (cf. UNESCO, 2004). Its overall aim is to prepare students to be able to create safe, supporting, challenging, engaging and inclusive learning environments across a wide range of socio-economic and cultural contexts. It also has an explicit brief to support the students' practicum. These foci reflect a crowded tertiary curriculum resulting from a prior institutional reorganisations that reduced the time available to systematically address these topics elsewhere in the curriculum.

In the process of operationalising the unit, two key decisions were made: first, to adopt a problem-based learning (PBL) model and second, to base the PBL program in and around real-life learning experiences to the extent that the course and practicum structures and requirements allowed. These decisions were made separately and independently at different times.

\subsection{Why PBL?}

The decision to adopt a PBL approach was based on the belief that in a program about effective learning environments, it was essential to adopt an effective adult learning environment model for the unit itself. PBL provided the opportunity to both create an appropriate student-centred team-based 
active learning environment, and to provide students with experiences of a different pedagogical approach to learning than those previously experienced in their course - a case of learning by modelling and immersion in which students were to act out the role of teachers developing policy as the basis of their work in CELE and to engage in genuine professional tasks.

While PBL has often been seen as an effective way to engage students in authentic tasks, it has also been criticised by some for its focus on solving 'problems' as opposed to acquiring knowledge through more traditional didactic approaches. However, such criticism fails to acknowledge both (a) the extensive incidental learning that occurs in the process of clarifying the problem, finding possible solutions, and in identifying the optimal solution, and (b) the fundamental importance of situative and contextualised learning (and practice) in supporting teachers' cognitive development and expertise (Putnam \& Borko, 1997). The latter point, of course, strongly supports the use of real-life learning experiences to provide the kind of rich, authentic learning that can support the development of meaningful reflective practice and 'validate' the students' coursework.

\subsection{The Role of Real-Life Learning}

The use of real-life learning experiences arose from the PBL context in three ways. First, the PBL task modelled a range a real-life professional roles; second, students used real school data as the basis of their work; third, by providing them with the opportunity to integrate their PBL task into their practicum program by 'sharing and validating' their developing policy with teachers and administrators in their practicum schools. This often led them to engage in extended discussions with teachers and administrators, and provided the students with real-life learning experiences as teachers and coordinators discussed and reviewed their particular school's policy and development issues - making strong links between their engagement in CELE and their real-life practicum experiences. This constant engagement and 'validation' of the nature and purpose of CELE in their practicum workplace (Fig. 2) provided the students with far deeper insights into the nature, development and purpose of policy than has generally been the case in the previous version of CELE which did not adopt this approach. 


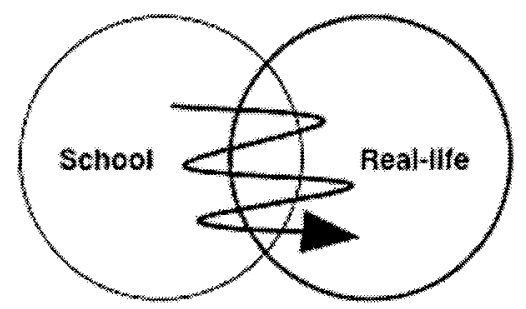

Figure 2. A blended-learning model to accommodate real-life learning

To firmly embed their work in real-life contexts, fictitious school data were provided for students to choose from, each representing a different kind of school based on 'like-school' data generated by a staff team member experienced in school reviews. The variables included in the data included state-wide testing results, the level of funding support for disadvantaged families (i.e., the Education Maintenance Allowance), demographics and cultural backgrounds of the school community, teacher-related issues such as profiles and attitudinal data, transition data and student retention rates. Student teams were required to interrogate the data in order to determine the nature of the 'problems' in their school, to then develop appropriate policy items to address them, and finally to develop and deliver a multimedia presentation of their policy recommendations at a notional school meeting. This presentation was assessed by a panel of university staff members and the students' class peers (Fig.3). The presentation was the only way in which the students' policy development was assessed. This gave the students the experience of evaluating policy in a real-life context.

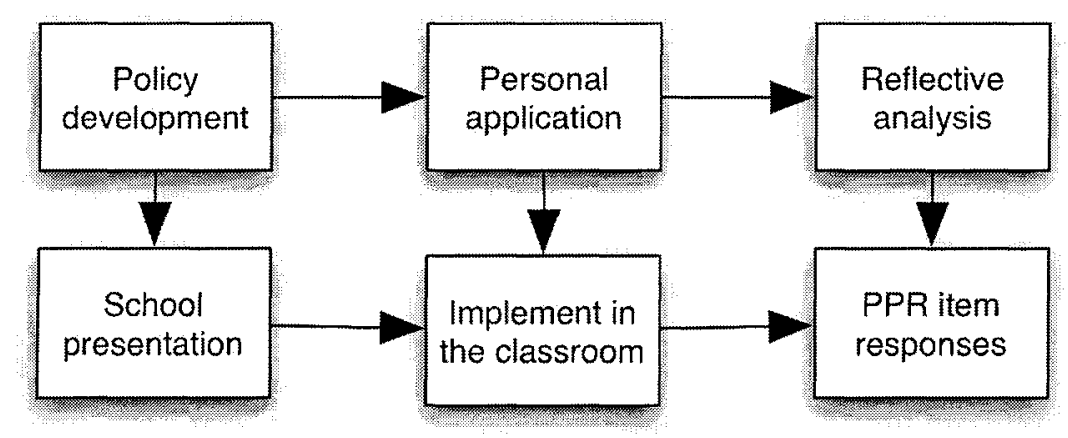

Figure 3. Tasks and assessment items

Later, the students had to demonstrate their ability to implement their policy items. Their ability to do this was peer-assessed by their team 
members using an evidence-based policy check list developed by each team. Students were encouraged to work closely with their practicum supervisors and other teachers in developing their lesson plans so that there was the opportunity to gain feedback and to learn from them. Finally, the students are required to reflect on their experiences in this program by developing a set of responses to likely annual review questions based on the themes of the unit and as developed in their tasks. Through this multi-stage assessment process, the students have to demonstrate their increasing understanding of policy development in a particular context, to apply it to their teaching, and to be able to justify their decision making to professional peers.

\subsection{The Victorian Institute of Teaching}

The Victorian Institute of Teaching (VIT) was established in 2001 in recognition of the need to provide a professional body for the teaching profession - one that would serve to enhance the professional status of teachers, to regulate entry to the teaching profession, and to ensure the maintenance of professional standards (VIT, 2004b). Whereas previously, new entrants to the profession could readily gain full registration based on meeting the academic and practicum requirements of their teacher education programme, new graduates are now given provisional registration for a period of 12 months to allow them time to develop and to enhance their repertoire of professional skills and to provide the opportunity to gather evidence of their ability to operate as in independent professional in their educational workplace (VIT, 2004a). All CELE tasks may be used as 'evidence' that can be incorporated into the students' current portfolios.

\section{THE USE OF ICT}

For the past 40 years, the use of ICT in Teacher Education has been problematic (Nicholson \& Underwood, 1996) and only recently have large scale initiatives attempted to provide clear pedagogical guidelines for educators (Cornu, 2001; UNESCO, 2004; Watson, 2001). Whereas many undergraduate students in CELE have basic ICT competencies, this is not necessarily the case with mature-age postgraduate students - those leaving another vocation to become a teacher. In both cases there is a real need to provide them with the basis for engaging in the professional and pedagogical use of ICT (as opposed to developing software skills).

Requiring CELE students to present their policy proposals as a basic multimedia presentation (PowerPoint and digital video) would introduce students to these basic technologies, and provide them with the experience of 
using them in a professional, as opposed to pedagogical, role. It was also decided that, consistent with the PBL approach, the staff would not provide formal instruction in the use of PowerPoint or iMovie software - student teams would be given a brief introduction to their functionality and a range of web-based support materials. In practice this approach worked well, with most teams having little trouble mastering the software.

The use of an ICT-based presentation in this unit served to force the students to make specific judgments about their materials and the approach to their presentation. They had to make hard decisions about what to focus on, how to represent their policy recommendations, and how to organise their team members presentation skills for an optimal presentation.

Procedural and developmental ICT issues arose in the development of the presentations that were similar to those teachers face in schools.. Some teams attempted to develop their media before their policy content was finished; others had difficulty in fitting their extensive policy recommendations to the confines dictated by the presentation format. There were also significant network and media-based issues.

The real value of the ICT component in CELE lies in its use as a focusing and contextualising tool (in the Activity Theory sense) that mediated the students interactions with peers, with policy issues, and with other team members in ways that forced extensive collaboration and engagement (cf. Roschelle \& Pea, 2002) through the need to create and perform, as well as learn the required ICT skills. In many ways it acts like Pea \& Kurlands' (1987) cognitive technologies for writing by providing a focusing and filtering mechanism through the dual dictates of media format and presentation context; these helped to drive the pathways between the university and workplace contexts (cf. Fig. 2). The development of a multimedia presentation gave the students a real-word/real-life context for using ICT, and has (anecdotally) given many of them the confidence to explore its further use in their teaching and professional roles.

\section{CONCLUSIONS}

The use of a real-life context, along with the use of ICT, to foster and model engagement and collaboration appears to have been effective in helping students to see both the importance of educational policy development in schools and the value of challenging and engaging learning environments. Course evaluation data are highly supportive of the use of both PBL and real-life contexts. This suggests that this focus should be maintained and extended to other units in the ESM. The role of ICT is critical, not because of its nature per se, but because of its use a mediating and focusing tool. 


\section{REFERENCES}

Berliner, D. (1991). Educational psychology and pedagogical expertise: New findings and new opportunities for thinking and training. Educational Psychologist, 2, 145-155.

Cornu, B. (2001). Winds of Change in the Teaching Profession (Report of the French National Commission for UNESCO). Paris: UNESCO.

Kane, J. (1999). Education, information, and transformation: essays on learning and thinking. Upper Saddle River, N.J.: Merrill.

Levin, B. B. (2003). Case Studies of Teacher Development: An In-Depth Look at How Thinking About Pedagogy Develops Over Time. Mahwah, NJ: Lawrence Erlbaum.

Nicholson, P. S. (1995). A Curriculum for Teachers or Learners? In D. Watson \& D. Tinsley (Eds.), Integrating Information Technology into Education (pp. 85-94). London: Chapman \& Hall.

Nicholson, P. S. (2004). E-Training or E-Learning? Towards a synthesis for the knowledgeera workplace. In P. S. Nicholson, Thompson, J., Ruhonen, M., Mulitsilta, J (Ed.), elearning solutions for professional organizations (pp. 360). New York: Kluwer.

Nicholson, P. S., \& deWacht, P. (2002). City to Surf: A peer-to-peer model of online professional development. An On-line collaborative model. In D. Passey \& M. Kendall (Eds.), Tele-learning 2002 (pp. 113-120). New York: Kluwer.

Nicholson, P. S., \& Underwood, J. (1996). Teacher education for primary and secondary education. In J. D. Tinsley \& T. J. Van Weert (Eds.), IFIP Windows to the Future (pp. 9397). Birmingham: Aston University.

Pea, R. D., \& Kurland, D. M. (1987). Cognitive Technologies for Writing. In E. Z. Rothkopf (Ed.), Review of Research in Education (Vol. 14, pp. 277-326). Washington DC: AERA

Putnam, R. T., \& Borko, H. (2000). What do new views of knowledge and thinking have to say about research on teacher learning? Educational Researcher, 29(1), 4-15.

Roschelle, J., \& Pea, R. (2002, Jan 7-11). A walk on the WILD side: How wireless handhelds may change CSCL. Paper presented at CSCL2002:, Boulder, Colorado.

UNESCO. (2004). Integrating ICT into Education: Lessons Learned. A Collective Case Study, Thailand. Bangkok: UNESCO APEID.

VIT. (2004a). Standards \& Professional Learning for Full Registration. Melbourne: Victorian Institute of Teaching.

VIT. (2004b). Standards (Professional Practice Standards). Melbourne: Victorian Institute for Teaching.

Watson, D. (2001). Pedagogy before Technology: Re-thinking the relationship between ICT and Teaching. Education and Information Technologies, 6(4), 251-266.

\section{ACKNOWLEDGEMENTS}

The unit Creating Effective Learning Environments that forms the context of this paper was developed by a cross-campus team of academics who constitute the Education Studies Major team within the Faculty of Education at Deakin University. This paper draws on the program as developed and conducted on the Burwood Campus and chaired by Dr. Geoff White. The positions argued and presented in this paper are those of the authors and may not necessarily represent those of other ESM team members. 